American Journal of Applied Sciences 5 (10): 1352-1357, 2008

ISSN 1546-9239

(C) 2008 Science Publications

\title{
A Fuzzy Mathematical Programming Approach to DEA Models
}

\author{
${ }^{1}$ A. Azadeh, ${ }^{1}$ S.F.Ghaderi, ${ }^{1}$ Z. Javaheri and ${ }^{2}$ M. Saberi \\ ${ }^{1}$ Department of Industrial Engineering and Center of Excellence for Intelligent \\ Based Experimental Mechanics and Research Institute of Energy Management and Planning, \\ College of Engineering, University of Tehran, P.O. Box 11365-4563, Iran \\ ${ }^{2}$ Department of Industrial Engineering, University of Tafresh, Iran
}

\begin{abstract}
Evaluating the performance of activities or organizations by traditional Data Envelopment Analysis (DEA) as efficiency frontier analysis models requires crisp input/output data. However, in real-world problems inputs and outputs are often imprecise. This study develops DEA models using imprecise data represented by fuzzy sets. An important outcome of assessing relative efficiencies within a group of Decision Making Units (DMUs) in fuzzy data envelopment analysis is to determine efficient DMUs. We find efficiency measures with fuzzy inputs and outputs via proposed model. An example using fuzzy data is presented for illustrative purposes. We apply this method in the application to the power generation sector of Iran.
\end{abstract}

Key words: Fuzzy logic, optimization, data envelopment analysis, power plant

\section{INTRODUCTION}

Efficiency frontier analysis has been an important approach of evaluating firms' performance in private and public sectors. There have been many efficiency frontier analysis methods reported in the literature. However, the assumptions made for each of these methods are restrictive. Each of these methodologies has its strength as well as major limitations especially sensitivity of frontier models to data causes to use a fuzzy mathematical programming approach to the assessment of efficiency with DEA models developed. The first study on fuzzy DEA was written in $1992^{[24]}$. The author of study explored the use of fuzzy set theory in decision making ${ }^{[24]}$. In this study, three types of fuzzy models (fuzzy mathematical programming, fuzzy regression and fuzzy entropy) were presented to illustrate the types of decisions and solutions that were achievable.

Moreover, in other study ranking methods is used for determining the efficiency of DMUs in inputoriented CCR model with fuzzy inputs and fuzzy outputs ${ }^{[13]}$. Also the relationship between DEA and Regression Analysis (RA) is studied. The CCR model and RA were considered as two special cases of the following goal programming problem:

$$
\begin{aligned}
& \text { DEARA(combinationo of DEA and RA) : } \\
& \begin{array}{cc}
\min & \mathrm{G}=\sum_{\mathrm{i}=1}^{\mathrm{n}}\left(\mathrm{a}_{\mathrm{i}} \rho_{\mathrm{i}}+\mathrm{b}_{\mathrm{i}} \eta_{\mathrm{i}}\right) \\
\text { s.t. } \quad & \mathrm{v}^{\mathrm{T}} \mathrm{y}_{\mathrm{i}}-\mathrm{u}^{\mathrm{T}} \mathrm{x}_{\mathrm{i}}=\rho_{\mathrm{i}}-\eta_{\mathrm{i}} \quad \mathrm{i}=1, \ldots, \mathrm{n} \\
& \mathrm{u}^{\mathrm{T}} \mathrm{x}_{0}=1 \\
& \mathrm{u}, \mathrm{v} \geq 0 \\
& \rho_{\mathrm{i}}, \eta_{\mathrm{i}} \geq 0
\end{array}
\end{aligned}
$$

The others develop some fuzzy versions of the classical DEA models by using some ranking methods based on the comparison of $\alpha$-cuts ${ }^{[26]}$. This makes an approach which is able to deal with inexact numbers or numbers in ranges, desirable. To deal quantitatively with imprecision in decision process, the notion of fuzziness is introduced ${ }^{[24]}$. In the conventional DEA approach, a set of weights which satisfies a set of constraints is selected to give the highest possible efficiency measure for each DMU. When some observations are fuzzy, the goal and constraints in the decision process become fuzzy as well. Since the DEA model is essentially a linear program, one straightforward idea is to apply the existing fuzzy Linear Programming (LP) techniques to the fuzzy DEA

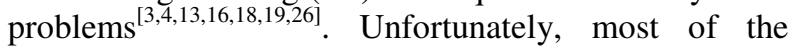
existing techniques only provide crisp solutions and others are only suitable for specific problems, although they are able to produce possibility distributions of the optimal objective values ${ }^{[3,4,13,1618,19,26]}$. There are articles

Corresponding Author: A. Azadeh, Department of Industrial Engineering, College of Engineering, University of Tehran, P.O. Box 11365-4563, Iran 
discussing efficiency measures when the observations are random, yet not fuzzy, in nature. A stochastic DEA model via specific membership functions to give a fuzzy programming interpretation is transformed $^{[21,23,25]}$.

Two DEA models are formulated: one model that gives on upper limit (best case) efficiency and one model that gives lower limit (worse case) efficiency ${ }^{[18]}$. Then an interval-valued efficiency can be constructed from these two extreme efficiencies. For the upper limit case, their model is the same as the CCR model. However, only crisp efficiency measures are provided.

On the whole, there are the three procedures that have been discussed on solving fuzzy DEA problems. The first is the procedure that solves the fuzzy DEA by the tolerance approach. The next is, solving the fuzzy DEA by the ranking approach and the last is to solve the fuzzy DEA by the parametric programming.

In this study we develop a method which is able to provide fuzzy efficiency measures for DMUs with fuzzy observations. Restated, the membership functions, rather than crisp measures, of efficiencies will be derived. The basic idea is to apply the $\alpha$-cuts to transform the fuzzy DEA model to a series of conventional crisp DEA models. The conventional DEA models are then solved by the LP method.

\section{DEA AND FUZZY DEA}

Data Envelopment Analysis (DEA) is a methodology based on a Linear Programming (LP) model for evaluating relative efficiencies of Decision Making Units (DMUs) with common inputs and outputs. It is used to ranking and analysis of DecisionMaking Units (DMUs), such as industries, universities, hospitals, cities, facilities layout, etc. ${ }^{[31]}$. The two basic DEA models are CCR and BCC with constant returns to scale and variable returns to scale, respectively ${ }^{[3,6]}$. Each DMU $\mathrm{k}$ is assigned the highest possible efficiency score $\left(h_{k} \leq 1\right)$ that the constraints allow from the available data, by choosing the optimal weights for the outputs and inputs. If DMU $\mathrm{k}$ receives the maximal value $h_{k}=1$, then it is efficient, but if $h_{k} \prec 1$, it is inefficient, since with its optimal weights, another DMU receives the maximal efficiency Eq. (1). Basically, the model divides the DMUs into two groups, efficient $\left(h_{k}=1\right)$ and inefficient $\left(h_{k} \prec 1\right)$, by identifying the efficient of the data. The original DEA model is not capable of ranking efficient units Therefore; the model is modified allowing for a ranking of the efficient units themselves.

The original fractional CCR model (1) evaluates the relative efficiencies of $n$ DMUs $(j=1, \ldots, n)$, each with $\mathrm{m}$ inputs and s outputs denoted by $x_{1 j}, x_{2 j}, \ldots, x_{m j}$ and $y_{1 j}, y_{2 j}, \ldots, y_{s j}$, respectively, by maximizing the ratio of weighted sum of outputs to the weighted sum of inputs.

(CCR ratio model)

$$
\begin{aligned}
& \operatorname{Max} \quad e_{j_{0}}=\frac{\sum_{r=1}^{s} u_{r} y_{r j}}{\sum_{i=1}^{m} v_{i} x_{i j}} \\
& \text { s.t. } \\
& \frac{\sum_{r=1}^{s} u_{r} y_{r j}}{\sum_{i=1}^{m} v_{i} x_{i j}} \leq 1, \quad j=1, \ldots n, \\
& u_{r}, v_{i} \geq 0, \quad r=1, \ldots, s, i=1, \ldots, m .
\end{aligned}
$$

In order to computational convenience the fractional programming model (2) is re-expressed in LP form as follows:

(CCR-LP model)

$$
\begin{aligned}
& \operatorname{Max}_{\mathrm{j}_{\mathrm{O}}}=\sum_{\mathrm{r}=1}^{\mathrm{s}} \mathrm{u}_{\mathrm{r}} \mathrm{y}_{\mathrm{rj}} \mathrm{o}_{\mathrm{O}} \\
& \text { s.t. } \\
& \sum_{\mathrm{r}=1}^{\mathrm{s}} \mathrm{u}_{\mathrm{r}} \mathrm{y}_{\mathrm{rj}}-\sum_{\mathrm{i}=1}^{\mathrm{m}} \mathrm{v}_{\mathrm{i}} \mathrm{x}_{\mathrm{ij}} \leq 0, \quad \mathrm{j}=1, \ldots \mathrm{n}, \\
& \sum_{\mathrm{i}=1}^{\mathrm{m}} \mathrm{v}_{\mathrm{i}} \mathrm{x}_{\mathrm{ij}}=1 \\
& \mathrm{u}_{\mathrm{r}}, \mathrm{v}_{\mathrm{i}} \geq 0, \mathrm{r}=1, \ldots, \mathrm{s}, \mathrm{i}=1, \ldots, \mathrm{m} .
\end{aligned}
$$

Suppose that there are $n$ DMUs, each of which consumes the same type of inputs and produces the same type of outputs. Let $\mathrm{m}$ be the number of inputs and let $r$ be the number of outputs. All inputs and outputs are assumed to be nonnegative, but at least one input and one output are positive. The following notation will be used throughout this study.

\section{NOTATIONS}

DMUi is the $\mathrm{i}^{\text {th }} \mathrm{DMU}$, DMUo is target DMU, 
$\mathrm{x}_{\mathrm{i}} \in \mathrm{R}^{\mathrm{m} \times 1}$ is the column vectore of inputs conxumedby DMUi

$\mathrm{x}_{\mathrm{o}} \in \mathrm{R}^{\mathrm{m} \times 1}$ is the column vectore of inputs of consumed by target DMU

$\mathrm{x} \in \mathrm{R}^{\mathrm{m} \times \mathrm{n}}$ is the matrix of inputs of all DMUs

$y_{i} \in R^{r \times 1}$ is the column vectore of inputs of consumed by DMUi

$\mathrm{y}_{\mathrm{o}} \in \mathrm{R}^{\mathrm{r} \times 1}$ is the column vectore of inputs of consumed by target $\mathrm{DMU}$

$\mathrm{y} \in \mathrm{R}^{\mathrm{r} \times \mathrm{n}}$ is the matrix of outputs of all outputs

$\lambda=\left(\lambda_{\mathrm{i}}\right)_{\mathrm{n} \times 1}, \lambda \in \mathrm{R}^{\mathrm{n}}$ is the column vectore of a linear combination of $\mathrm{n}$ DMUs

$\theta$ is the objective value (efficiency) of the CCR model

$\mathrm{u} \in \mathrm{R}^{\mathrm{m} \times 1}$ is the column vector of input eweights

$v \in R^{m \times 1}$ is the column vector of output weights

The CCR model with fuzzy data can be written as:

$$
\begin{aligned}
& \text { Max } e_{j_{O}}=\sum_{r=1}^{s} u_{r} \tilde{y}_{r_{j}} \\
& \text { s.t. } \\
& \sum_{r=1}^{s} u_{r} \tilde{y}_{r j}-\sum_{i=1}^{m} v_{i} \tilde{x}_{i j} \leq 0, \quad j=1, \ldots n, \\
& \sum_{i=1}^{m} v_{i} \tilde{x}_{i j}=1 \\
& u_{r}, v_{i} \geq 0, r=1, \ldots, s, i=1, \ldots, m .
\end{aligned}
$$

where, ${ }^{\text {‘ }}$ indicate the fuzziness.

There are different types of fuzzy numbers, but triangular fuzzy numbers are more useful so that we consider the inputs and outputs of DMUs as triangular fuzzy numbers.

Therefore, (3) can be written as follows:

$$
\tilde{x}_{\mathrm{ij}}=\left(\mathrm{x}_{\mathrm{ij}}^{\mathrm{m}}, \mathrm{x}_{\mathrm{ij}}^{1}, \mathrm{x}_{\mathrm{ij}}^{\mathrm{u}}\right) \text { and } \tilde{y}_{\mathrm{rj}}=\left(\mathrm{y}_{\mathrm{rj}}^{\mathrm{m}}, \mathrm{y}_{\mathrm{rj}}^{1}, \mathrm{y}_{\mathrm{rj}}^{\mathrm{u}}\right)
$$

Let

$$
\begin{aligned}
& \operatorname{Max} e_{j_{0}}=\sum_{r=1}^{s} u_{r}\left(y_{r o}^{m}, y_{r o}^{1}, y_{r o}^{u}\right) \\
& \text { s.t. } \\
& \sum_{r=1}^{s} u_{r}\left(y_{r j}^{m}, y_{r j}^{1}, y_{r j}^{u}\right)-\sum_{i=1}^{m} v_{i}\left(x_{i j}^{m}, x_{i j}^{1}, x_{i j}^{u}\right) \leq 0, \\
& j=1, \ldots n, \\
& \sum_{i=1}^{m} v_{i}\left(x_{i o}^{m}, x_{i o}^{1}, x_{i o}^{u}\right)=1 \\
& u_{r}, v_{i} \geq 0, r=1, \ldots, s, i=1, \ldots, m .
\end{aligned}
$$

Model (5) is a nonlinear programming. There are various methods to solve it .In most of these methods for solving is to convert the possibilistic programming problem using $\alpha$-cut, the intervals in both sides of the constraints are compared with each other. There are many methods for comparing the intervals; hence many methods may be suggested for solving intervalprogramming problem.

\section{THE PROPOSED MODEL}

The basic idea is to transform the fuzzy CCR model into a crisp linear programming problem by applying an alternative $\alpha$-cut approach. Thereby, the problem is converted to an interval programming. Different methodologies have been suggested for the comparison of the intervals in this study based on Tang Cheng Method is worked.

At first, we use $\alpha$-cut to convert fuzzy DEA into interval programming as follows:

$$
\begin{aligned}
& \operatorname{Max} e_{j_{0}}=\sum_{r=1}^{s} u_{r}\left(\alpha y_{\text {ro }}^{m}+(1-\alpha) y_{\text {ro }}^{1}, \alpha y_{\text {ro }}^{m}+(1-\alpha) y_{\text {ro }}^{u}\right) \\
& \text { s.t. } \\
& \sum_{r=1}^{s} u_{r}\left(\alpha y_{r j}^{m}+(1-\alpha) y_{r j}^{1}, \alpha y_{r j}^{m}+(1-\alpha) y_{r j}^{u}\right)- \\
& \sum_{i=1}^{m} v_{i}\left(\alpha x_{i j}^{m}+(1-\alpha) x_{i j}^{1}, \alpha x_{i j}^{m}+(1-\alpha) x_{i j}^{u}\right) \leq 0 \\
& j=1, \ldots n, \\
& \sum_{i=1}^{m} v_{i}\left(\alpha x_{i o}^{m}+(1-\alpha) x_{i o}^{1}, \alpha x_{i o}^{m}+(1-\alpha) x_{i o}^{u}\right)=1 \\
& u_{r}, v_{i} \geq 0, r=1, \ldots, s, i=1, \ldots, m
\end{aligned}
$$

With considering our method model change into as follows this model gives upper bound of efficiency and next model gives lower bound of efficiency.

$$
\begin{aligned}
& \max e_{j_{o}}=\sum_{r=1}^{s} u_{r}\left(\alpha y_{r o}^{m}+(1-\alpha) y_{r o}^{u}\right) \\
& \text { s.t. } \sum_{i=1}^{m} v_{i}\left(\alpha x_{i j}^{m}+(1-\alpha) x_{i j}^{1}\right) \geq \sum_{r=1}^{s} u_{r}\left(\alpha y_{r j}^{m}+(1-\alpha) y_{r j}^{u}\right) \\
& \sum_{i=1}^{m} v_{i}\left(\alpha x_{i o}^{m}+(1-\alpha) x_{i o}^{u}\right)=1 \\
& \max _{j_{o}}^{m} \sum_{r=1}^{s} u_{r}\left(\alpha y_{r o}^{m}+(1-\alpha) y_{r o}^{1}\right) \\
& \text { s.t. } \quad \sum_{i=1}^{m} v_{i}\left(\alpha x_{i j}^{m}+(1-\alpha) x_{i j}^{u}\right) \geq \sum_{r=1}^{s} u_{r}\left(\alpha y_{r j}^{m}+(1-\alpha) y_{r j}^{1}\right) \\
& \sum_{i=1}^{m} v_{i}\left(\alpha x_{i o}^{m}+(1-\alpha) x_{i o}^{1}\right)=1
\end{aligned}
$$


The above model is equivalent to a the fuzzy linear programming problem with $\alpha \in(0,1]$. It is noted that for each $\alpha$, we have an optimal solution.

\begin{tabular}{llllll}
\multicolumn{6}{l}{ Table 1: Lower bound result } \\
\hline Powerplant product & $\alpha=0$ & $\alpha=0.25$ & $\alpha=0.5$ & $\alpha=0.75$ & $\alpha=1$ \\
\hline Montazer & 0 & 1 & 0.92 & 0.93 & 0.89 \\
Besat & 0 & 0.87 & 0.75 & 0.82 & 1 \\
Firozi & 0 & 0.71 & 0.63 & 0.67 & 1 \\
Salimi & 0 & 1 & 1 & 1 & 1 \\
Shazand & 0 & 1 & 1 & 1 & 1 \\
Rajaie & 0 & 1 & 1 & 1 & 1 \\
Beheshti & 0 & 1 & 0.92 & 0.95 & 0.93 \\
Tabriz & 0 & 1 & 0.86 & 0.91 & 0.9 \\
Mofateh & 0 & 1 & 0.94 & 0.95 & 0.91 \\
Biston & 0 & 1 & 0.91 & 1 & 1 \\
Ramin & 0 & 1 & 1 & 1 & 1 \\
Medhaj & 0 & 1 & 0.91 & 0.91 & 0.92 \\
Bandar & 0 & 0.99 & 0.85 & 0.89 & 0.87 \\
Zarand & 0 & 0.79 & 0.69 & 0.76 & 1 \\
Esfehan & 0 & 1 & 1 & 1 & 1 \\
Montazeri & 0 & 1 & 0.94 & 1 & 1 \\
Tos & 0 & 1 & 0.9 & 0.95 & 0.95 \\
Mashhad & 0 & 0.82 & 0.71 & 0.77 & 0.86 \\
Iranshahr & 0 & 1 & 1 & 1 & 1 \\
\hline
\end{tabular}

Thus, we can provide the decision maker a solution table with different $\alpha$ in $[0,1)$.

\section{THE CASE STUDY}

Evaluation of conventional thermal steam-electric performance may be described conveniently within an engineering framework. In this framework, pertinent inputs are the fuel quantity consumed and installed power, which is the maximum nominal power the plants are initially designed. On the other hand labor inputs contribute to production through control and maintenance services, which also require some capital. The output is, of course, electrical energy production. But by notice of studies about efficiency measurement of thermal power generations in Iran which indicate that labor isn't an effective factor ${ }^{[30]}$. in our study, electric power (in megawatt hour) generated from thermal power plants in each DMU $(\mathrm{P})$ is used as the output variable, while capital (C), fuel (F) and internal power (Ic) are three inputs used for power generation. Capital is measured in terms of installed thermal generating capacity in megawatt (MW) Various natural elements have been used as fuel in the production of electric power in various steam plants in Iran (natural gas, gas oil and mazute). The choice of fuel depends on many factors such as availability, cost and environmental concerns and each fuel has its limitations. Our figures measure fuel consumption in terms of Tera Joule (TJ). In other words, our figures have already adjusted for the quality of fuel used in different plants. Internal power is the amount of energy consumed (in megawatt hour) within the site (for electrically powered equipment etc.). We purpose a method to evaluate the performance of power plants and find their efficiencies. Lower

Table 2: Upper bound result

\begin{tabular}{llllll}
\hline Power plant product & $\alpha=0$ & $\alpha=0.25$ & $\alpha=0.5$ & $\alpha=0.75$ & $\alpha=1$ \\
\hline Montazer & 0 & 2.17 & 1.24 & 0.97 & 0.89 \\
Besat & 0 & 2.08 & 1.37 & 1.02 & 1 \\
Firozi & 0 & 1.06 & 0.58 & 2.3 & 1 \\
Salimi & 0 & 2.38 & 1.34 & 1.07 & 1 \\
Shazand & 0 & 2.49 & 1.48 & 1.1 & 1 \\
Rajaie & 0 & 2.45 & 1.4 & 1.1 & 1 \\
Beheshti & 0 & 2.36 & 1.33 & 1.03 & 0.93 \\
Tabriz & 0 & 2.22 & 1.26 & 0.98 & 0.9 \\
Mofateh & 0 & 2.2 & 1.26 & 0.99 & 0.91 \\
Biston & 0 & 2.47 & 1.42 & 1.12 & 1 \\
Ramin & 0 & 2.39 & 1.38 & 1.08 & 1 \\
Medhaj & 0 & 2.55 & 1.54 & 1.03 & 0.92 \\
Bandar & 0 & 2.09 & 1.2 & 0.94 & 0.87 \\
Zarand & 0 & 4.49 & 5.36 & 1.57 & 1 \\
Esfehan & 0 & 2.36 & 1.37 & 1.08 & 1 \\
Montazeri & 0 & 2.5 & 1.4 & 1.09 & 1 \\
Toos & 0 & 2.29 & 1.31 & 1.03 & 0.95 \\
Mashhad & 0 & 2.62 & 1.15 & 0.89 & 0.86 \\
Iranshahr & 0 & 2.15 & 1.24 & 0.97 & 1 \\
\hline & & & & &
\end{tabular}

Table 3: Result of two method

\begin{tabular}{lll}
\hline Power plants & Ordinary method & Proposed method \\
\hline Montazer & 0.89 & 0.89 \\
Besat & 0.88 & 1 \\
Firozi & 0.66 & 1 \\
Salimi & 1 & 1 \\
Shazand & 1 & 1 \\
Rajaie & 1 & 1 \\
Beheshti & 0.93 & 0.93 \\
Tabriz & 0.9 & 0.9 \\
Mofateh & 0.91 & 0.91 \\
Biston & 0.99 & 1 \\
Ramin & 1 & 1 \\
Medhaj & 0.92 & 0.92 \\
Bandar & 0.87 & 0.87 \\
Zarand & 0.83 & 1 \\
Esfehan & 0.88 & 1 \\
Montazeri & 1 & 1 \\
Tos & 0.95 & 0.95 \\
Mashhad & 0.81 & 0.86 \\
Iranshahr & 0.87 & 1 \\
\hline
\end{tabular}

bound is is expressed in Table 1. Also, upper bound is is expressed in Table 2.

Then in order to validate this approach we compare these results on $\alpha=1$ with results ordinary DEA model. With regard to objective function of proposed model is maximizing so that we consider upper bound of values. We can see Table 3 of comparing two methods. 


\section{CONCLUSION}

We transformed the fuzzy CCR model into a crisp linear programming problem by applying an alternative $\alpha$-cut approach. Thereby, the problem was converted to an interval programming. Different methodologies have been suggested for the comparison of the intervals in this study based on Tang Cheng Method is worked. We used $\alpha$-cut to convert fuzzy DEA into interval programming. In proposed model, two linear programming problems were solved to obtain the efficiency of a given DMU with symmetrical triangular fuzzy number. This model is an application of fuzzy set theory in DEA.

\section{REFERENCE}

1. Arnade, C.A., 1994. Using data envelopment analysis to measure international agricultural efficiency and productivity, United States Department of Agriculture. Economic Research Service, Tech. Bull., 1831: 1-30.

2. Banker, R.D., A. Charnes and W.W. Cooper, 1984. Some models for estimating technical and scale inefficiency in data envelopment analysis. Manage. Sci., 30: 1078-1092.

3. Banker, R.D., H. Chang and W.W. Cooper, 1996. Simulation studies of efficiency, returns to scale and misspecification with nonlinear functions in DEA. Ann. Oper. Res., 66: 233-253.

4. Charnes, A. and W.W. Cooper, 1959. Chanceconstrained programming. Manage. Sci., 6: 73-79.

5. Charnes, A., W.W. Cooper and E. Rhodes, 1978. Measuring the efficiency of decision-making units. Eur. J. Oper. Res., 2: 429-444.

6. Charnes, A., W.W. Cooper, B. Golany and L. Seiford, 1985. Foundation data envelopment analysis of Pareto-Koopmans effcient empirical production functions. J. Econ., 30: 91-107.

7. Charnes, A., W.W. Cooper, A.Y. Lewin and L.M. Seiford, 1994. Data Envelopment Analysis: Theory, Methodology and Application. Kluwer Academic Publishers, London.

8. Cooper, W.W., K.S. Park and J.T. Paster, 1999. RAM: A range adjusted measure of ineffciency for use with additive models and relations to other models and measures in DEA. J. Prod. Anal., 11: 5-42.

9. Cooper, W.W., L.M. Seiford and K. Tone, 2000. Data Envelopment Analysis: A Comprehensive Text with Models, Applications. Reference and DEA-Solver Software, Kluwer Academic Publishers, London.
10. Cooper, W.W. and K. Tone, 1997. Measures of ineffciency in data envelopment analysis and stochastic frontier estimation. Eur. J. Oper. Res., 99: 72-88.

11. Dubois, D. and H. Prade, 1988. Possibility Theory: An Approach to Computerized Processing of Uncertainty. Plenum Press, New York.

12. Fang, S.C. and S. Puthenpura, 1993. Linear Optimization and Extensions: Theory and Algorithms. Prentice-Hall, Englewood Cli/s, NJ.

13. Guo, P. and H. Tanaka, 2001. Fuzzy DEA: Aperceptual evaluation method. Fuzzy Sets Syst., 119: 149-160.

14. Kahraman, C. and E. Tolga, 1998. Data envelopment analysis using fuzzy concept. 28th International Symposium on Multiple-Valued Logic., 338-343.

15. Kao, C. and S.T. Liu, 2000. Fuzzy efficiency measures in data envelopment analysis. Fuzzy Sets Syst., 113: 427-437.

16. Lertworasirikul, S., 2001. Fuzzy data envelopment analysis for supply chain modeling and analysis. Dissertation Proposal in Industrial Engineering, North Carolina State University.

17. Liu, B., 1999. Uncertain Programming. A WileyInterscience Publication, New York.

18. Meada, Y., Entani, T., Tanaka, H., 1998. Fuzzy DEA with interval efficiency. 6th European Congress on Intelligent Techniques and Soft Computing, 2: 1067-1071.

19. Seiford, L.M. and R.M. Thrall, 1990. Recent development in DEA: The mathematical programming approach to frontier analysis. J. Econ., $46: 7-38$.

20. Sengupta, J.K., 1992. A fuzzy systems approach in data envelopment analysis. Comput. Math. Appl., 24: 259-266.

21. Sengupta, J.K., 1995. Dynamics of Data Envelopment Analysis: Theory of Systems Eaciency. Kluwer Academic Publishers, London.

22. Wang, X., Kerre, E.E., 2001. Reasonable properties for the ordering of fuzzy quantities (I). Fuzzy Sets Syst., 118: 375-385.

23. Wang, X. and E.E. Kerre, 2001. Reasonable properties for the ordering of fuzzy quantities (II). Fuzzy Sets Syst., 118: 387-405.

24. Zadeh, L.A., 1978. Fuzzy sets as a basis for a theory of possibility, Fuzzy Sets Syst., 1: 3-28.

25. Zimmermann, H.J., 1996. Fuzzy Set Theory and Its Application. Kluwer Academic Publishers, London. 
26. Leon, T., V. Liern and J.L. Ruiz, 2003. A fuzzy mathematical programming approach to the assessment of efficiency with DEA models. Fuzzy Sets Syst., 139 (2): 407-419.

27. Lertworasirikul, S. and S.C. Fang, 2003. Fuzzy data envelopment analysis (DEA): A possibility approach. Fuzzy Sets Syst., 139.

28. Buckley, J.J., 1989. Solving possibilistic linear programming problems. Fuzzy Sets Syst., 31: 329-341.

29. Delgado, M., J.L. Verdegay and M.A. Vila, 1990. Relating different approaches to solve linear programming problems with imprecise costs. Fuzzy Sets Syst., 37: 33- 42.
30. EmamiMeibodi, A., 1998. Efficiency considerations in the electricity supply industry: The Case of Iran. Ph.D. Thesis, University of Surrey.

31. Azadeh, A., S.F. Ghaderi, M. Anvari and M. Saberi, 2006. Measuring performance electric power generations using artificial neural networks and fuzzy clustering. In Proceeding of the 2006 IEEE International Conference on Industrial Electronics - IECON'06 (Paris). 